\section{A SUCCESSFUL MODEL OF DELIVERING INITIAL HEALTH ASSESSMENTS (IHA) FOR CHILDREN AND YOUNG PEOPLE IN CARE (CYPIC) IN A PANDEMIC}

Katherine Shelley, Kerry Holt, Latha Tirupati Kumara. UK

\subsection{6/bmjpo-2021-RCPCH.198}

Background In the UK, from March 2020 in-person consultations were limited to reduce COVID-19 transmission. Statutory guidance recommends that these happen in a timely manner when a child enters into care. RCPCH standards state that IHAs completed by telephone should ideally be completed by in-person reviews within 3-6 months. Hence a dual clinic model of virtual, followed by short face to face appointments, was developed to minimise contact whilst ensuring quality of consultations. Follow up appointments focused on growth, physical and developmental examination and allowed the clinician to speak to the Child or Young Person in Care (CYPiC). Objectives

- To review documentation for compliance with regulations

- To seek users' feedback and make service improvements

Methods Records for 23 of 24 users who attended virtual IHAs from April to July 2020 were reviewed from the

\begin{tabular}{llll}
\multicolumn{2}{l}{ Abstract 363 Table 1} & & \\
\hline Information & & Available & $\begin{array}{l}\text { Not } \\
\text { available }\end{array}$ \\
\hline Immunisations & & $17 \%$ \\
Neonatal screening & & $83 \%$ & $21 \%$ \\
Health forms & Mother & $79 \%$ & $33 \%$ \\
& Father & $67 \%$ & $46 \%$ \\
Obstetric information & & $54 \%$ & $83 \%$ \\
Summaries & GP & $17 \%$ & $30 \%$ \\
& Social & $70 \%$ & $30 \%$ \\
Discussion & worker & $70 \%$ & $54 \%$ \\
with & Mother & & $67 \%$ \\
& Father & $46 \%$ & $21 \%$ \\
\hline
\end{tabular}

Abstract 363 Table 2 Documentation of 11 out of 13 parameters was more complete compared to the previous year

\begin{tabular}{llll}
\hline & & 2019 & 2020 \\
\hline $\begin{array}{lll}\text { Action plan complete } \\
\text { SMART plans }\end{array}$ & & $100 \%$ & $100 \%$ \\
Consent (if capacity) & & $90 \%$ & $100 \%$ \\
Seen alone/invited & & $20 \%$ & $100 \%$ \\
Documented & Growth & $90 \%$ & $91 \%$ \\
& Health & $100 \%$ & $100 \%$ \\
& promotion & $60 \%$ & $78 \%$ \\
& Wishes & & \\
& Behavioural & $80 \%$ & $96 \%$ \\
Action plan & needs & $100 \%$ & $96 \%$ \\
considers & Dental history & $36 \%$ & $75 \%$ \\
& Emotional needs & $56 \%$ & $96 \%$ \\
& Physical needs & $100 \%$ & $100 \%$ \\
& Wishes & $30 \%$ & $96 \%$ \\
\hline
\end{tabular}

Abstract 363 Table 3

\begin{tabular}{lll}
\hline & Agree a lot & Undecided/Don't know \\
\hline Did the virtual clinic offer a good service? & $81 \%$ & $12.5 \%$ \\
Was the follow up face to face clinic useful? & $87.5 \%$ & $6 \%$ \\
\hline
\end{tabular}

electronic CYPiC database (excluding one child who ceased being in care after the virtual clinic). Service users were asked to provide written feedback after each appointment.

Results Waiting times for face-to-face appointments ranged from 16-124 days, median 47 days (within recommended timeframe). $74 \%$ had the same clinician for both appointments, ensuring continuity of care. Appropriate consent was taken in all cases. Additionally, consent was taken from every young person with capacity to consent. 91\% were invited to be seen alone. Wishes and feelings were taken into account in all but one child. Most (but not all) of the relevant information to aid completion of the IHA was available.

Response rate to the feedback forms was $70 \%$.

Positive comments included 'comfortable in own home more relaxed' and 'treated same as if in clinic'. There were 2 negative comments - 'video link not working' and 'uncomfortable wearing a mask'. No users mentioned attending 2 appointments as a negative aspect.

Conclusions Despite limitations in delivering services during the pandemic, this dual model of clinic delivery ensured a high quality service. Feedback was positive as was user engagement with this model which emphasized child-centric care. Learning from this can be applied to other clinics such as review health assessments. Holistic CYPiC statutory assessments through efficient use of virtual technology, in combination with outcome focused in person reviews may become more common place in the future.

\section{4 CASE REPORT: RARE CASES OF ANTENATAL DIAGNOSIS OF CONGENITAL ARACHNOID CYST - REVIEW OF 2 CASES}

Barbara Paquete, Katie McArthur, Anna Paweletz, Sanjeev Rath. UK

\subsection{6/bmjpo-2021-RCPCH.199}

Background Case 1: Mum was a 30 years old multiparous woman and known smoker. Antenatal ultrasound scan showed an intracranial arachnoid cyst measuring $14 \times 13 \mathrm{~mm}$, that continued to grow in subsequent scans.

Baby was born at $37+5$ weeks and day 2 cranial ultrasound scan showed a large cystic lesion on the suprasellar region measuring $17 \times 17 \mathrm{~mm}$.

MRI on day 6 of life showed a large suprasellar arachnoid cyst $18 \times 22 \mathrm{~mm}$ in size which was causing significant mass effect displacing and compressing the midbrain and basal ganglia. As the baby was clinically asymptomatic and progressing and developing appropriately, the neurosurgical team opted for a conservative management with a multidisciplinary approach with involvement of ophthalmology, endocrinology, and local general paediatricians for close monitoring of growth and development as well as regular blood tests (Renal function and pituitary function). He remains well until the present and is currently 15 months old. 